\title{
Chromatic and Achromatic Vision of Macaques: Role of the P Pathway
}

\author{
William H. Merigan \\ Department of Ophthalmology, University of Rochester Medical Center, Rochester, New York 14642
}

Chromatic and achromatic contrast sensitivity were measured in a human observer, 2 normal macaque monkeys, and 3 monkeys with severe toxicant-induced damage to the parvocellular projecting retinogeniculate pathway $(P$ cell-deficient monkeys). Damage to the $P$ pathway was produced by the oral administration of acrylamide monomer (Eskin and Merigan, 1986). Contrast sensitivity was measured in all subjects with isochromatic luminance gratings, as well as isoluminant chromatic gratings, modulated along several directions of a color space that represents color-opponent and luminance contrast (Krauskopf et al., 1986). The chromatic and achromatic sensitivity of the control monkeys was virtually identical to that of the human observer. Chromatic sensitivity of the $P$ cell-deficient monkeys, measured at a low spatial frequency $(0.3 \mathrm{c} / \mathrm{deg})$, along a constant-blue color axis, was $0.9-1.5 \mathrm{log}$ units lower than that of controls. Similar losses were seen along a tritanopic confusion axis and along 2 intermediate axes of color direction. Chromatic thresholds measured at higher spatial frequency $(2.0 \mathrm{c} / \mathrm{deg})$ were similarly reduced. Counterphase-modulated chromatic gratings were used to test color sensitivity over a range of temporal frequencies up to $15 \mathrm{~Hz}$, and the loss of color vision was substantial over the entire range of frequencies. The luminance contrast sensitivity of the $P$ cell-deficient monkeys for stationary gratings decreased after exposure by $0.5-0.8$ log units.

These results indicate that the chromatic and achromatic spatial vision of macaques is very similar to that of humans. They also suggest that the $P$ pathway plays an important role in macaque chromatic sensitivity at all spatial frequencies, as well as achromatic sensitivity at high spatial and lower temporal frequencies.

Parallel retinogeniculate visual pathways have been demonstrated by both anatomical and physiological studies in macaque monkeys (see Lennie, 1980; Shapley and Perry, 1986), and by anatomical methods in humans (Rodieck et al., 1985). The very different characteristics of neurons in the 2 major parallel path-

Received Apr. 20, 1988; revised Aug. 11, 1988; accepted Aug. 12, 1988

This work was supported by NSF Grant BNS-8518858 and by Grants ES-01247 and EY-0139. We thank Thomas A. Eskin, William J. Vaughn, Cheryl Ruff-Neri, and James Lynch for assistance in conducting the experiments, and Peter Lennie, David R. Williams, and Tatiana Pasternak for critically reading the manuscript

Donald D. Johnson, NTID Eye and Ear Clinic, kindly tested the human observer for congenital color defects.

Correspondence should be addressed to William H. Merigan, Department of Ophthalmology, Box 314, University of Rochester Medical Center, Rochester, NY 14642.

Copyright (c) 1989 Society for Neuroscience $0270-6474 / 89 / 030776-08 \$ 02.00 / 0$ ways suggest that thesc pathways may play different roles in visual function. The $M$ pathway (which projects to magnocellular layers of the geniculate) includes about $10 \%$ of retinal ganglion cells (Perry et al., 1984), and these have large retinal dendritic fields, large cell bodies, and stout axons. Physiologically, neurons of this pathway have high luminance contrast sensitivity and excellent temporal frequency resolution and are responsive to low luminance stimuli (Kaplan and Shapley, 1982; Hicks et al., 1983; Virsu et al., 1987; Purpura et al., 1988). On the other hand, the $\mathrm{P}$ (parvocellular projecting) pathway includes about $80 \%$ of retinal ganglion cells, and these have small somata, small compact dendritic fields, and a dense spatial distribution across the retina (Leventhal et al., 1981; Perry et al., 1984). Physiologically, P pathway neurons show color opponency, low sensitivity, and only moderate temporal resolution (Gouras and Zrenner, 1979; Kaplan and Shapley, 1982; Derrington et al., 1984).

Consideration of their anatomical and physiological properties suggests that the $P$ pathway may be specialized for color vision and acuity, and the $\mathrm{M}$ pathway for temporal resolution and the detection of low-luminance stimuli. At present, the only direct evidence for such specialization is Merigan and Eskin's (1986) observation of achromatic spatiotemporal vision in monkeys with scvere damage to the $P$ pathway. They concluded that the $P$ pathway plays an important role in visual acuity as well as contrast detection at low temporal frequencies.

Damage to the $P$ retinal ganglion cells by acrylamide monomer produces reliable inactivation of the $P$ pathway. We have reported detailed observations of selective $\mathbf{P}$ cell degeneration in 2 acrylamide-dosed monkeys (Eskin and Merigan, 1986), and have confirmed these observations in 7 additional monkeys. Severe damage to $P$ retinal ganglion cells over much of the retina is shown by greatly reduced anterograde transport of wheat germ agglutinin-conjugated horseradish peroxidase (WGA-HRP), little or no cytochrome oxidase activity, and marked neuronal atrophy and gliosis in parvocellular layers of the lateral geniculate. However, continued activity of small numbers of parvocellular neurons in the geniculate is suggested by preserved cytochrome oxidase activity in a few scattered neurons in some monkeys. Relative sparing of the $M$ pathway was shown by the same morphological measures and by physiological recording of single cell responses in magnocellular layers of the geniculate of one acrylamide dosed monkey (G. Sklar and W. H. Merigan, unpublished observations). The reliability of these findings suggests that monkeys in the present study will show the same pattern of selective degeneration when they are examined morphologically.

The present study used acrylamide-exposed monkeys to examine the role of the $P$ pathway in the chromatic and achromatic 


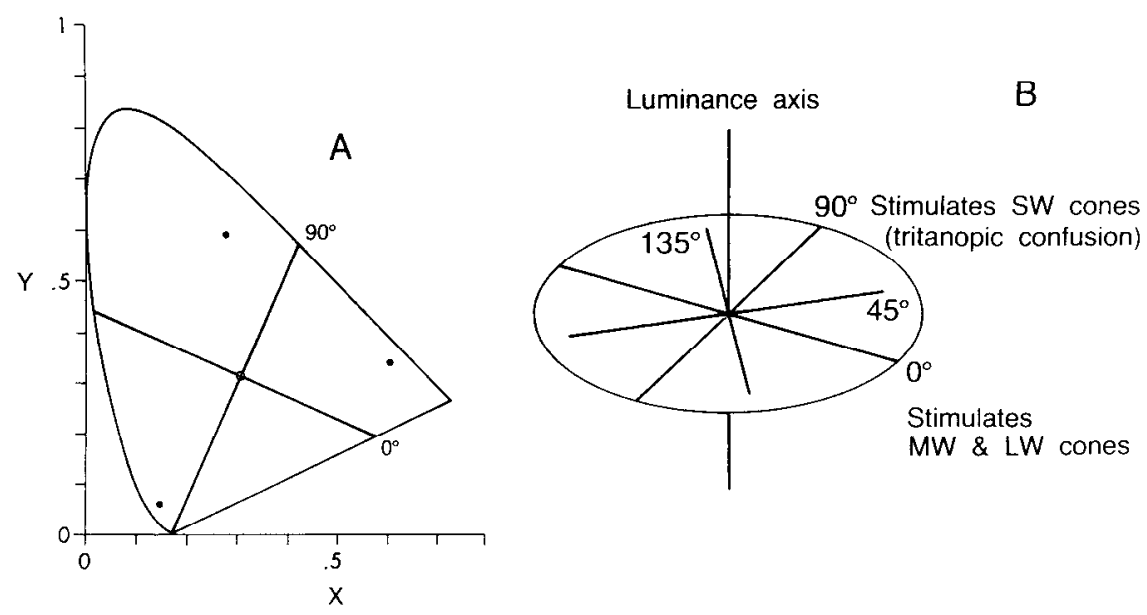

Figure 1. A, CIE coordinates of the $0^{\circ}$ (constant-blue) and $90^{\circ}$ (tritanopic confusion) axes of the color space used here. The CIE coordinates of the 3 phosphors of the color monitor are shown as filled circles. B. Color space used in the present study. This space was described by Krauskopf and coworkers (e.g., Krauskopf et al., 1986) and is based on the earlier work of MacLeod and Boynton (1979). The circle represents the isoluminant plane, the major axes of this plane being the tritanopic confusion $\left(90^{\circ}\right)$ axis, which provides no modulation of the middle wavelength $(M W)$-long wavelength ( $L W$ ) opponent mechanism, and the constant-blue $\left(0^{\circ}\right)$ axis, which provides no modulation of short-wavelength-sensitive cones $(S W)$ [and therefore no modulation of the SW-(MW-LW) opponent mechanism]. The luminance axis is orthogonal to the isoluminant plane and passes through the white point. The elevation of any color axis in this space is the angle between it and the isoluminant plane $\left(0^{\circ}\right)$; the luminance axis has an elevation of $90^{\circ}$.

vision of the primate. The sensitivity of normal monkeys was compared with that of a human observer and that of monkeys with severe, toxicant-induced damage to their $P$ pathway. The color vision of normal macaques and humans was very similar, as would be expected from previous comparisons of their receptor sensitivity (Bowmaker et al., 1978; Dartnall et al., 1983; Nunn et al., 1984; Schnapf et al., 1987), and color vision (DeValois et al., 1974). Results from P cell-deficient monkeys support physiological evidence in indicating that the $P$ pathway plays a dominant role in the primate's color vision, as well as an important role in its achromatic vision.

\section{Materials and Methods}

Animals. Five feral, adult, female macaque monkcys (Macaca nemestrina) were used. Two (112 and 410) served as normal controls. The other $3(561,117$, and 310$)$ were given $10 \mathrm{mg} / \mathrm{kg} / \mathrm{d}$ acrylamide monomer orally $5 \mathrm{~d}$ /week until marked peripheral neuropathies were evident (dosing is summarized in Table 1), a treatment regimen that results in severe damage to $\mathrm{P}$ retinal ganglion cells (Eskin and Merigan, 1986). The acrylamide administration also produces, over the last few days of dosing, a transitory limb weakness and loss of interest by the monkey in its surroundings. Each monkey's status was monitored closely during this period by its appetite and fluid intake, and highly palatable nutritional supplements were provided as needed.

When visual thresholds were tested, each monkey had free access to Purina monkey chow, supplemented regularly with fresh fruit, and was water-deprived for approximately $20 \mathrm{hr}$ before daily testing.

The human subject was a corrected myope with normal color vision as measured by the Nagel anomaloscope, the Farnsworth-Munsell 100hue test and the Ishihara test plates.

Apparaius and procedures. The monkeys were seated in an acrylic chair facing a 19 inch color monitor (Conrac 7211) at a distance of 152 $\mathrm{cm}$. An unilluminated white mask surrounded two $14 \mathrm{~cm}$ high by $9 \mathrm{~cm}$ wide $\left(9^{\circ} \times 6^{\circ}\right)$ oval stimulus areas separated by $2 \mathrm{~cm}$. Stimuli were presented in one of these areas on each trial. Two circular response switches, located on the panel in front of the monkey, could be pressed to indicate whether the stimulus was presented in the right or left stimulus area. The monkeys were rewarded with fruit juice for correct responses, and each session consisted of 200 stimulus presentations.

Stimuli were horizontal sinusoidal gratings modulated in luminance, chromaticity, or both, within a color space derived from the work of MacLeod and Boynton (1979) (Krauskopf et al., 1986). Stimuli were generated at $60 \mathrm{~Hz}$ frame rate by an Adage 3006 raster display unit, controlled by a PDP-11/73 computer. Figure 1 illustrates this color space and its location in CIE coordinates. Between trials, both stimulus panels were a uniform white $(20 \mathrm{fL}, \mathrm{CIE}$ coordinates $x=0.315, y=$ 0.315 ). After a $4 \mathrm{sec}$ intertrial interval, a grating stimulus was presented randomly on either the right or left display. Contrast onset was smoothed in time, its waveform was $1 / 2$ cycle of a raised cosine of $0.25 \mathrm{~Hz}$. A tone, indicating the opportunity to respond, was turned on $1 \mathrm{sec}$ after the start of stimulus onset, and remained on until a response was made. For all threshold measurements described below, the mean luminance and the spatial and temporal frequency of the stimulus remained constant within a session, and either the chromatic or luminance contrast was varied according to a staircase that increased stimulus contrast after every error and reduced stimulus contrast with probability 0.25 after every correct choice. Daily thresholds were determined by interpolation to 0.75 on the resulting psychometric function, and at least 3 determinations were made for each stimulus condition.

In calculating contrast we made an attempt to compare the various stimulus conditions in terms of the stimulation they provided to ganglion cells. For luminance contrast, or the luminance component of a non-isoluminant chromatic stimulus, we calculated the contrast delivered to any cone or ganglion cell type as the Michelson contrast $\left(L_{\max }-L_{\min }\right) /\left(L_{\max }+L_{\min }\right)$, where $L_{\max }$ was the point of highest luminance and $L_{\min }$ the point of lowest luminance in the grating. For chromatic contrast along a constant-blue (reddish-greenish) axis, we calculated, from the response spectrum of human cones (cone fundamentals) of Smith and Pokorny (1975), the contrast delivered to middlewavelength cones (i.e., the Michelson contrast of a chromatic stimulus for such cones) and that delivered to long-wavelength cones, and added the absolute value of these contrasts. This approach rests on the assumption (which has not as yet been examined) that both excitatory and inhibitory inputs into reddish-greenish chromatically opponent ganglion cells arise from single cone types. Chromatic contrast along the tritanopic confusion axis (approximately yellowish-bluish) was taken as the contrast delivered to the short-wavelength cones. Chromatic contrast for intermediate directions in color space were taken as the vector sum of the 2 above measures. Mixed chromatic and luminance contrasts were calculated as the vector sum of the individual contrasts.

Sensitivity along different color directions. Chromatic contrast sensitivity was measured along the 4 color directions of the isoluminant plane shown in Figure $1\left(0^{\circ}, 45^{\circ}, 90^{\circ}\right.$, and $\left.135^{\circ}\right)$. Color directions $0^{\circ}$ and $90^{\circ}$ appear to stimulate separate second-stage color-opponent mechanisms (Krauskopf et al., 1982; Derrington et al., 1984), while directions $45^{\circ}$ and $135^{\circ}$ each stimulate both of these opponent mechanisms (Krauskopf et al., 1986). Stimuli wcre $9^{\circ} \times 6^{\circ}$ oval stationary gratings of 0.3 


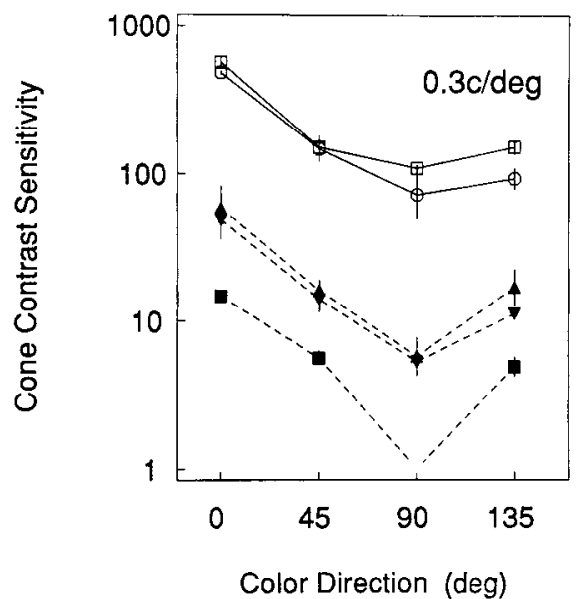

Figure 2. Chromatic contrast sensitivity for 4 directions of color modulation in the isoluminant plane: $0^{\circ}=$ constant-blue, $90^{\circ}=$ tritanopic confusion, and $45^{\circ}$ and $135^{\circ}=$ intermediate directions.

c/deg spatial frequency on a white background, and measurements for different color directions were interleaved.

Dependence of chromatic sensitivity on temporal frequency. Spatiotemporal chromatic contrast sensitivity was determined with counterphase gratings modulated along a $0^{\circ}$ (constant-blue) color axis. Stimuli were $9^{\circ} \times 6^{\circ}$ oval isoluminant gratings of $0.3 \mathrm{c} / \mathrm{deg}$ spatial frequency, modulated at 2,8 , and $15 \mathrm{~Hz}$. The waveform of modulation onset was $1 / 2$ cycle of a raised cosine of $0.25 \mathrm{~Hz}$.

Influence of stimulus extent on chromatic sensitivity. Chromatic contrast sensitivity for stimuli of different sizes was measured along a $0^{\circ}$ (constant-blue) axis for $2 \mathrm{c} / \mathrm{deg}$ stimuli over a wide range of stimulus areas. The largest stimuli were the $9^{\circ}$ by $6^{\circ}$ patches used in previous measurements. Results for these stimuli were compared with those for circular stimulus patches of $3^{\circ}$ and $1^{\circ}$ diameter.

Verifying the isoluminance of chromatic stimuli. The appropriate luminance ratio of the reddish and greenish bars of the constant-blue stimulus was evaluated by holding the chromatic direction constant, and varying the elevation (relative luminance of the two) out of the isoluminant plane from $-90^{\circ}$ to $90^{\circ}$. Chromatic contrast sensitivity was measured with stationary gratings of low spatial frequency $(0.3 \mathrm{c} / \mathrm{deg})$ for each of these elevations. Since chromatic sensitivity is substantially higher than achromatic sensitivity at low spatial frequencies (Mullen, 1985), the elevation that produced the highest sensitivity was taken as the isoluminant point under these spatiotemporal conditions.

Comparison of achromatic and chromatic contrast sensitivity. Chromatic contrast sensitivity was tested with stationary isoluminant gratings of 0.3 and $2.0 \mathrm{c} / \mathrm{deg}$ along constant-blue and tritanopic confusion axes for all monkeys. The same measures were made at $0.3,2.0$, and $6.0 \mathrm{c} / \mathrm{deg}$ for a human obscrver. Achromatic contrast scnsitivity for stationary gratings was measured with high-resolution display oscilloscopes (p-31 phosphor) for spatial frequencies from 0.4 to about 30 $\mathrm{c} / \mathrm{deg}$. (Since this phosphor is green, these stimuli are technically isochromatic luminance gratings, but for simplicity are termed achromatic gratings.) A few points were also measured with black-white luminance gratings using the color television, and these were in close agreement with those determined with the high-resolution displays. In addition, achromatic contrast sensitivity was determined in both $P$ cell-deficient monkeys and controls with $10 \mathrm{~Hz}$ counterphase-modulated gratings of $0.7 \mathrm{c} / \mathrm{deg}$, stimulus conditions under which $\mathbf{P}$ cell-deficient monkeys have shown little loss of contrast sensitivity (Merigan and Eskin, 1986).

\section{Results}

The only measured threshold on which the P cell-deficient monkeys were not inferior to controls was the determination of achromatic contrast sensitivity for $10 \mathrm{~Hz}, 0.7 \mathrm{c} / \mathrm{deg}$ counterphase gratings. The sensitivity of $P$ cell-deficient monkeys 310 , 561 , and 117 for such stimuli was 80,102 , and 115 , respectively. Comparable sensitivity, 80 and 122 , was found for control mon-

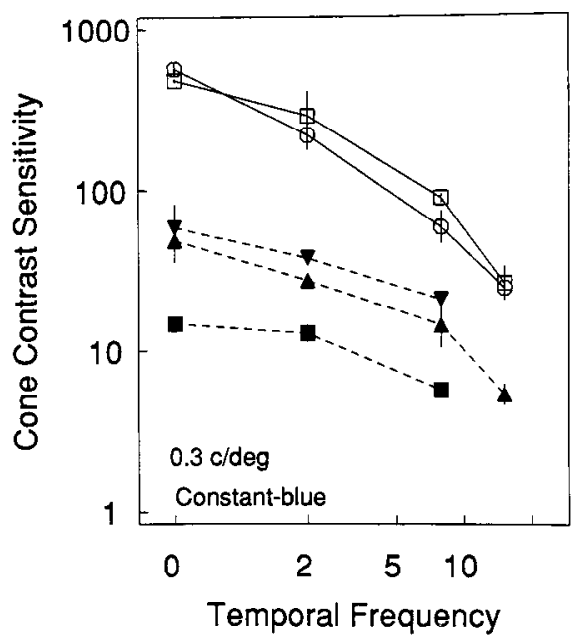

Figure 3. Chromatic contrast sensitivity as a function of the frequency of counterphase modulation of a $0.3 \mathrm{c} / \mathrm{deg}$ grating modulated along a constant-blue axis in the isoluminant plane. Error bars, \pm SEM.

keys, indicating no decrease in high temporal, low spatial frequency achromatic sensitivity due to $\mathrm{P}$ cell loss. As is shown in the next few paragraphs, $\mathrm{P}$ cell-deficient monkeys were inferior to controls on all other measures of chromatic and achromatic sensitivity.

Figure 2 shows the chromatic contrast sensitivity of control subjects and $\mathrm{P}$ cell-deficient monkeys for 4 directions of color modulation in the isoluminant plane. Open circles show the mean $( \pm$ SEM $)$ of the mean thesholds of the normal control monkeys, while open squares represent the data $( \pm$ SEM) of the human observer. The chromatic sensitivity of these observers was approximately 6 times greater for constant-blue modulation $\left(0^{\circ}\right)$ than for modulation along a tritanopic confusion axis $\left(90^{\circ}\right)$. Sensitivity to modulation along intermediate color directions $\left(45^{\circ}\right.$ and $\left.135^{\circ}\right)$ fell between that for the major axes.

The chromatic sensitivity of the 3 acrylamide-exposed monkeys (filled symbols) was greatly reduced compared with that of controls. The sensitivity of monkeys 117 and 561 (filled triangles) was about $1 \log$ unit (factor of 10 ) below that of controls, while the sensitivity of monkey 310 (filled squares) was about $1.5 \log$ unit (factor of 30) lower, except at the $90^{\circ}$ direction, at which no threshold could be measured.

Modulation sensitivity for $0.3 \mathrm{c} / \mathrm{deg}$ counterphase-modulated gratings, as a function of temporal frequency, is illustratcd in Figure 3 . The mean sensitivity of the control monkeys ( \pm SEM) is shown as open circles and that of the human subject as open squares. Modulation sensitivity of the controls was greatest at low temporal frequencies and declined at higher frequencies. The $3 \mathrm{P}$ cell-deficient monkeys (filled symbols) had reduced modulation sensitivity at all temporal frequencies.

Figure 4 demonstrates that chromatic contrast sensitivity for a $2 \mathrm{c} / \mathrm{deg}$ constant-blue $\left(0^{\circ}\right)$ grating increased with stimulus size for the control monkeys (open circles), the human observer (open squares), and 2 of the P cell-deficient monkeys (filled triangles). The magnitude of the increase was approximately $1 / 3$ $\log$ unit for an increase in stimulus area of about $2 \log$ units. Sensitivity did not increase with stimulus size in the P celldeficient monkey with the greatest visual loss, monkey 310 (filled squares).

Figure 5 shows, for 5 subjects, the effect on sensitivity for a constant-blue stimulus of tilting the axis of color modulation 


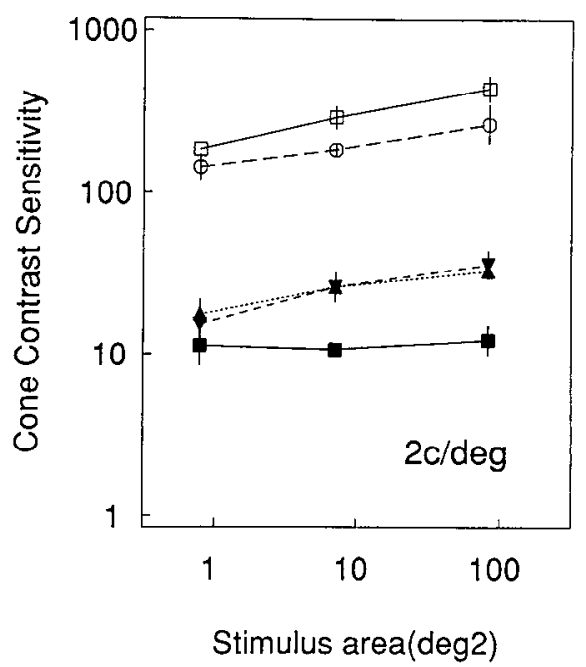

Figure 4. Chromatic contrast sensitivity along the $0^{\circ}$ (constant-blue) color axis in the isoluminant plane as a function of stimulus extent. Abscissa values refer to the area of the stimulus in degrees ${ }^{2}$ of visual angle. The largest stimulus was oval in shape and subtended $9^{\circ}$ vertically by $6^{\circ}$ horizontally. The $3^{\circ}$ and $1^{\circ}$ diameter stimuli were circular.

out of the calculated isoluminant plane. The elevation marked 0 represents sensitivity measured in the calculated isoluminant plane, while positive elevations represent greater brightness of the reddish bars of the grating, and elevations less than 0 represent greater brightness of greenish bars. At elevations of 90 and -90 , the stimuli contained only luminance contrast. Open circles and triangles show data of 2 control monkeys, and open squares that of a human observer. All had peak chromatic sensitivity for this low spatial frequency at the calculated isoluminant point. Acrylamide-treated monkey 117 (filled squares) also showed greater sensitivity for chromatic stimuli (near elevation 0) than achromatic stimuli, while monkey 310 (filled circles) had approximately equal sensitivity to chromatic and achromatic gratings.

The chromatic and achromatic contrast sensitivity of 6 subjects for stationary gratings is compared in Figure 6. The upper half of the figure shows results for 2 normal monkeys and a human subject (WM). The lower half of the figure shows results for 3 monkeys $(117,561$, and 310$)$ after acrylamide exposure. Achromatic contrast sensitivity of controls is indicated by open triangles and a dotted curve. Achromatic contrast sensitivity of the $\mathrm{P}$ cell-deficient monkeys before acrylamide exposure is indicated by a dotted curve, and after acrylamide exposure by filled triangles and a solid curve. The chromatic sensitivity of controls along the $0^{\circ}$ direction of color modulation is shown by open circles and a solid line. The range of chromatic sensitivities of these 2 normal monkeys is shown by stippling on the figures for the treated monkeys, while the chromatic sensitivity of the treated monkeys after acrylamide exposure is shown by filled circles and a solid line. The achromatic contrast sensitivity of the treated monkeys was about $0.5-0.8$ log units lower than that of controls. Chromatic contrast sensitivity was about 0.9-1.5 $\log$ units lower.

Figure 7 compares the peak chromatic to the peak achromatic contrast sensitivity of control subjects and $P$ cell-deficient monkeys. Results for 3 control monkeys and the human observer are shown as open symbols, and those for the $\mathrm{P}$ cell-deficient monkeys as filled symbols. Figure 7 illustrates a parallel decline in chromatic and achromatic contrast sensitivity in all subjects

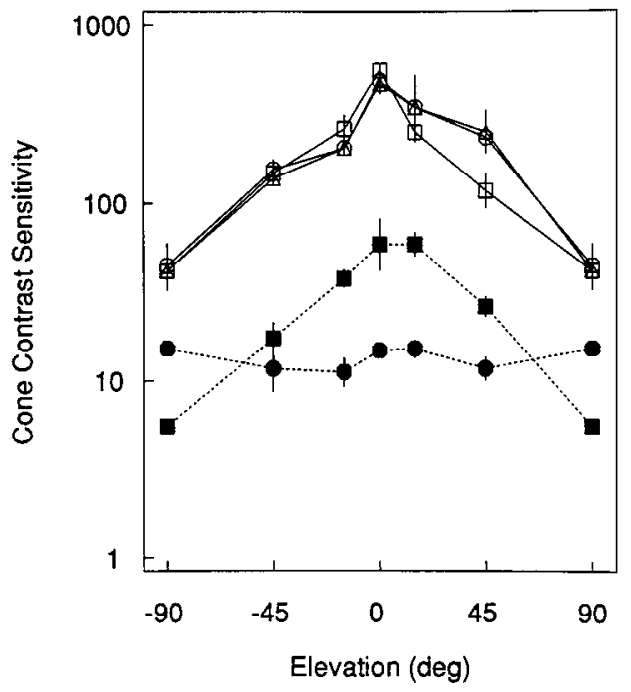

Figure 5. Chromatic contrast sensitivity for a $0.3 \mathrm{c} / \mathrm{deg}$ (constant-blue) grating as a function of elevation in the color space. The $0^{\circ}$ elevation represents the calculated isoluminant planc and $90^{\circ}$, the luminance axis. Thresholds were measured at elevations of $-90^{\circ},-45^{\circ},-15^{\circ}, 0^{\circ}, 15^{\circ}$, $45^{\circ}$, and $90^{\circ}$. Contrast threshold was calculated as the vector sum of the luminance and chromatic contrast. Error bars, \pm SEM.

except monkey 310 . This one monkey had a profound loss of chromatic sensitivity, but its loss of achromatic sensitivity was no greater than that seen in other acrylamide-exposed monkeys.

\section{Discussion}

Neurotoxicant-induced degeneration of retinal ganglion cells of the $P$ pathway resulted in a profound, and apparently permanent, disruption of macaque color vision. Color vision was severely reduced over a 3 octave range of spatial frequencies and a wide range of both temporal frequencies and stimulus sizes. The magnitude of sensitivity loss was similar along both of the major axes of the color space used, as well as along the 2 intermediate axes. The loss of color vision was accompanied by a substantial reduction in achromatic contrast sensitivity at low, but not at higher, temporal frequencies. The relative sparing of achromatic sensitivity at higher temporal frequencies supports other evidence in indicating a lack of major damage to the $M$ visual pathway. The close relationship observed across monkeys between the loss of chromatic sensitivity and that of low temporal frequency achromatic sensitivity suggests that the $P$ visual pathway may mediate both of these capacities.

\section{Nature of the observed color vision loss}

The color space used in this study describes chromatic stimuli in terms of their effects on color-opponent mechanisms and, thus, is well suited to studying the effects of loss of color-opponent ganglion cells. It has recently been shown that the majority of $P$ cells in the macaque lateral geniculate respond best to chromatic stimuli modulated along a constant-blue $\left(0^{\circ}\right)$ axis, and the remainder to modulation along a tritanopic confusion $\left(90^{\circ}\right)$ axis (Derrington et al., 1984; Young, 1986). That these 2 color directions are fundamental for primate color vision was demonstrated by Krauskopf et al. (1982) with the observation that chromatic vision along these 2 dimensions was independent, that is, did not undergo cross-adaptation.

While the extent of chromatic loss in the P cell-deficient monkeys varied from about 1 to $1.5 \mathrm{log}$ units, there was no sub- 
Figure 6. Chromatic and achromatic contrast sensitivity of one human subject (WM), 2 control monkeys $(112,410$, and 3 acrylamide-exposed macaques (561, 117, 310). Normal achromatic sensitivity is shown with open triangles and dotted lines, and achromatic sensitivity after acrylamide dosing with filled triangles and solid lines. Chromatic sensitivity (plotted as the reciprocal of cone contrast) is shown for the constant-blue axis of controls (open circles in the upper plots and stippling in the lower plots) and acrylamide-dosed monkeys (filled circles). Error bars, \pm SEM.

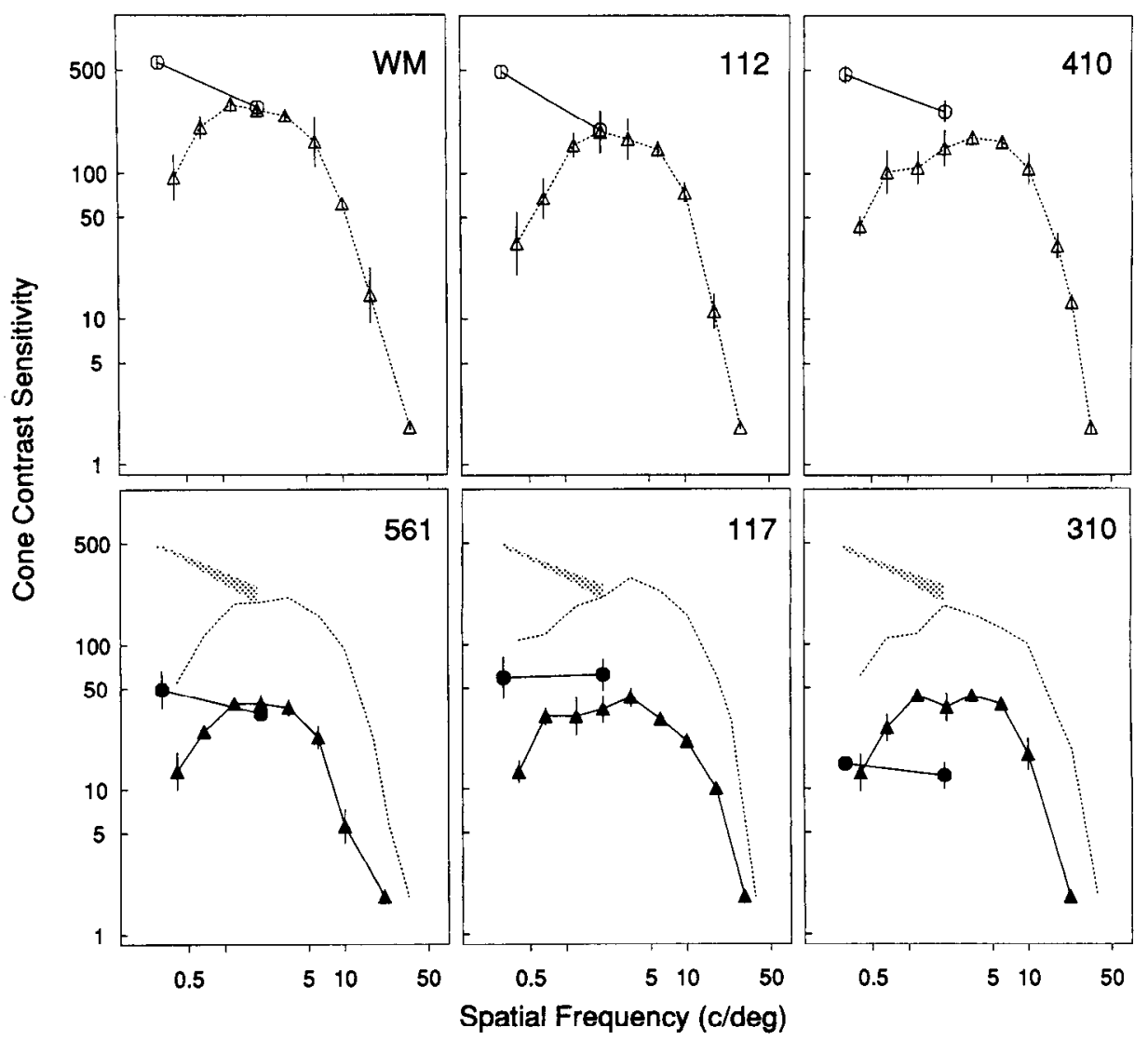

stantial evidence of a selective effect on 1 of these 2 directions of color space. This finding suggests that neither of the 2 types of color-opponent retinal ganglion cell was selectively vulnerable to acrylamide exposure, although sensitivity along a tritanopic confusion axis does appear to be especially vulnerable in certain retinal diseases (e.g., Adams, 1982).

Chromatic sensitivity along intermediate axes of this color space has been studied by Krauskopf et al. (1986), who concluded that such performance reflected the action of higherorder mechanisms combining signals from the constant-blue

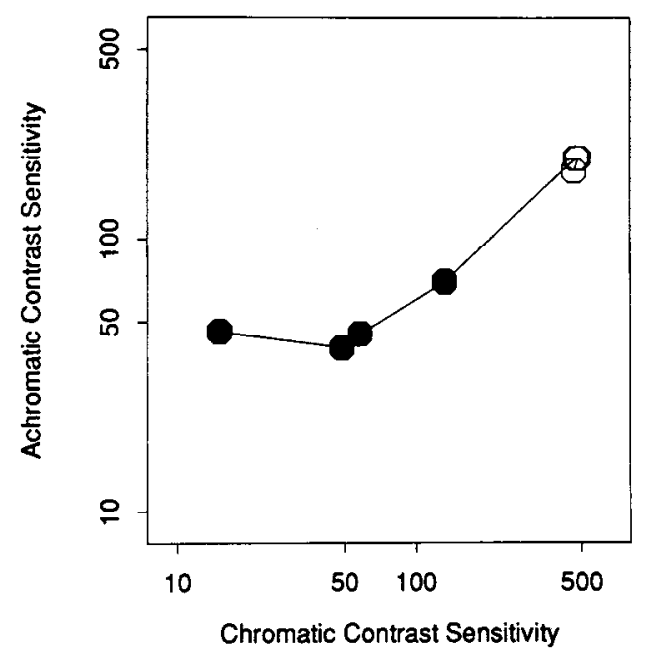

Figure 7. Peak achromatic sensitivity of each subject is plotted as a function of its chromatic sensitivity at $0.3 \mathrm{c} / \mathrm{deg}$. and tritanopic confusion mechanisms. In this study, we found that sensitivity along these intermediate axes was reduced by approximately the same amount as along the major axes.

Although the present study measured loss of chromatic vision with sensitivity measures, it is useful to extend these results to deficits in color discriminations. Any 2 color stimuli could be represented in the color space used in this experiment (Krauskopf et al., 1982), and their separation along constant-blue and tritanopic confusion axes determined. Pairs of stimuli should be discriminable if their separation along either axis exceeds that of the observer's threshold along that axis. The greatly elevated thresholds of the acrylamide-exposed monkeys in this study suggest a severe loss of color discrimination ability. Quantitative prediction of such losses would require that chromatic thresholds be independent of absolute location along the 2 chromatic axes (i.e., of chromatic adaptation). Boynton and Kambe (1986) have shown that this assumption is true to a first approximation.

\section{Relation of chromatic to achromatic vision}

The most striking difference between chromatic (van der Horst and Bouman, 1969; Kelly, 1983) and achromatic (Koenderink et al., 1978; Kelly, 1979) spatiotemporal vision is that chromatic sensitivity peaks at lower spatial frequencies than does achromatic sensitivity (also see Sperling and Harwerth, 1971; KingSmith and Carden, 1976; Thornton and Pugh, 1983). When stimuli are not stabilized, chromatic vision is low pass and achromatic vision bandpass across spatial frequency, and chromatic vision falls off much more rapidly at higher temporal and spatial frequencies than achromatic vision. In addition, chromatic sensitivity is slightly greater than achromatic sensitivity 
at lower spatial and temporal frequencies, when both are measured in units of cone contrast (Varner et al., 1984; Stromeyer et al., 1987). All of the above features were present in the thresholds of normal macaques and the human subject in the present study, although chromatic thresholds were not measured at high spatial frequencies because of the difficulty of controlling, in macaques, the chromatic aberration in the retinal image (Bedford and Wyszecki, 1957).

The shift of chromatic, relative to achromatic, vision toward lower spatial frequencies may be partly accomplished at the level of individual P cells. Ingling and Martinez-Uriegas (1983) have pointed out that any cell with chromatically opponent center and surround will show only luminance sensitivity at higher spatial frequencies. Further, the response of such a cell to chromatic gratings will not show the low-frequency falloff in sensitivity that is typical of the response to luminance gratings. Thus, the behavior of individual chromatically opponent $P$ cells may account, in part, for the low-pass spatial frequency tuning and the lower spatial resolution of chromatic than luminance vision.

On the other hand, the reduced chromatic sensitivity at higher temporal frequencies is less clearly connected to $\mathrm{P}$ cell properties. Psychophysical chromatic sensitivity declines sharply at temporal frequencies of 10-20 $\mathrm{Hz}$. (Kelly, 1983), whereas the chromatic response of individual color-opponent $P$ cells decreases more slowly at high temporal frequencies (B. B. Lee, personal communication). Thus, the poor sensitivity of primates to color at higher temporal frequencies may reflect temporal filtering of $\mathbf{P}$ cell responses by later structures in the visual system.

\section{Role of $P$ and $M$ pathways in achromatic vision}

The present results suggest that the $P$ pathway plays an important role in the detection of achromatic contrast at both high spatial and low temporal frequencies. This finding and the evidence outlined below are inconsistent with the identification of achromatic vision with the $M$ pathway and chromatic vision with the P pathway (Shapley and Perry, 1986). Physiological studies have established that the $P$ pathway carries both luminance and chromatic information (Wiesel and Hubel, 1966; Shapley and Kaplan, 1982; Derrington et al., 1984), and there is every reason to believe that both are utilized.

A major role for the $P$ pathway in the detection of high spatial frequency luminance stimuli is suggested by the approximately 8 -fold higher density of $\mathrm{P}$ cells in the macaque retina (Perry et al., 1984), by the smaller dendritic fields of $P$ cells in macaque (Perry et al., 1984) and human (Rodieck et al., 1985), and by the smaller $P$ cell receptive field centers in macaque retina (De Monasterio and Gouras, 1975) and geniculate (Derrington and Lennie, 1984). Indeed, Thibos (1986) has reported that the visual acuity of humans at different eccentricities from the fovea is well matched to the spatial sampling density of $\mathbf{P}$ ganglion cells in the primate. As pointed out below, there is a transition of $\mathbf{P}$ cell response from luminance and chromatic response at low spatial frequencies to only luminance at higher spatial frequencies (Ingling and Martinez-Uriegas, 1983). Thus, the present finding of reduced achromatic sensitivity at high spatial frequencies due to loss of the $\mathbf{P}$ pathway is not unexpected.

That loss of $P$ cells should cause a severe reduction in achromatic sensitivity at low temporal frequencies is less expected. The sensitivity of individual $M$ cells in the retina or lateral geniculate is substantially higher than that of $P$ cells, and several reports have concluded, possibly on this basis, that the $\mathrm{P}$ path-
Table 1. Dosing history of P cell-deficient monkeys

\begin{tabular}{llll} 
Monkey & $\begin{array}{l}\text { Doses first } \\
\text { period }\end{array}$ & $\begin{array}{l}\text { Interval } \\
\text { (weeks) }\end{array}$ & $\begin{array}{l}\text { Doses } \\
\text { second } \\
\text { period }\end{array}$ \\
\hline 310 & 50 & - & - \\
117 & 39 & 20 & 39 \\
561 & 50 & 41 & 50 \\
\hline
\end{tabular}

way is not responsive to low contrasts (Tootell, 1982; Livingston and Hubel, 1987). There are 2 difficultics with this conclusion.

First, $M$ cells appear to show a greater low spatial frequency falloff in sensitivity than do P cells (Hicks et al., 1983; Derrington and Lennie, 1984). Thus, the superiority of $M$ cell over $P$ cell sensitivity is most marked at middle to higher temporal frequencies - in fact, at the very temporal frequencies at which contrast sensitivity was virtually normal in the acrylamide-exposed monkeys of this study.

Second, it has been argued that probability summation among low-sensitivity $\mathrm{P}$ cells can result in high, $\mathrm{P}$ cell-mediated, psychophysical luminance sensitivity (Merigan and Eskin, 1986). It is noteworthy that the chromatic sensitivity of individual $\mathbf{P}$ cells is also substantially lower than chromatic sensitivity measured psychophysically (Derrington et al., 1984; Shapley and Kaplan, 1986). Thus, probability summation among $P$ cells appears to be important in chromatic as well as achromatic vision.

\section{Role of the $P$ and $M$ pathways in chromatic vision}

Findings in the present study indicate that the $\mathbf{P}$ pathway plays a dominant, and perhaps exclusive, role in the perception of chromatic stimuli. This is certainly in keeping with physiological findings of color-opponent properties in $\mathrm{P}$, but not $\mathrm{M}$, cells (De Monasterio and Gouras, 1975; Derrington et al., 1984; Lee et al., 1987), and the relation of the major or "cardinal" directions of color opponency in human psychophysical measurements to the response of geniculate $P$ neurons (Krauskopf et al., 1982; Derrington et al., 1984). The most obvious difficulty with this account, the finding that the chromatic sensitivity of individual $P$ cells is very low compared with that measured psychophysically (see above), may reflect substantial probability summation among individual $P$ cells.

An alternative approach to the study of $P$ and $M$ cell roles in color vision would be to examine the chromatic sensitivity that could be mediated by the $M$ pathway. The physiological signature of color opponency is that the phase of a cell's response to chromatic alternation is not reversed when the luminance ratio of the alternated colors is manipulated. For example, a color-opponent cell might respond with an increase in firing to a reddish stimulus and a decrease in firing to a greenish stimulus despite great variation in the relative luminance of these stimuli. Reversal of the phase of response (for example, greater firing to a reddish stimulus under some conditions and to a greenish stimulus under others) does occur in nonopponent cells of the $M$ pathway when the luminance ratio of alternated colors is varied, giving a nulling of the cell's response (Kruger, 1979; Lee et al., 1987) or appearance of a frequency-doubled response (Schiller and Colby, 1983; Hurlbert et al., 1987) at some luminance ratio. This phase reversal is characteristic of a lumi- 
nance response without a chromatic response and constitutes a complete loss of color information.

On the other hand, the use of spatially or temporally isoluminant stimuli cannot insure that the $M$ pathway will be silenced. Temporal alteration of isoluminant stimuli can result in a frequency-doubled response (see above) in some $\mathrm{M}$ cells, which conveys the rate of alternation but not the identity of the alternating colors. Even if no frequency-doubled response were produced at isoluminance, there is a second mechanism by which the $\mathrm{M}$ pathway could respond to isoluminant stimuli. Derrington et al. (1984) showed that cone input to geniculate $\mathrm{M}$ cells was often not balanced, giving individual cells slightly different null points to chromatic stimuli. Indeed, studies of the nulling of $\mathrm{M}$ geniculate cells have found somewhat different null points (luminance ratios of chromatic stimuli that give minimal response) for different M cells (e.g., Shapley and Kaplan, 1986). The implication of this result is that any null point used for the observer will null the response of only a portion of the $\mathrm{M}$ cells; those not nulled may show a luminance response to the nominally "isoluminant" stimulus (but see Cavanagh, 1988). A further difficulty for the testing of isoluminant vision is that isoluminance changes with eccentricity (see Livingston and Hubel, 1987, for a recent description of this phenomenon).

It is clear from these considerations that it is difficult to rule out some role of the M pathway when studying chromatic sensitivity with a detection paradigm. This is particularly problematic in the present study because, while chromatic sensitivity was depressed, all treated monkeys had both some residual chromatic sensitivity and sparing of the $M$ pathway. However, we believe that the remaining chromatic sensitivity was likely due to surviving $P$ cclls. If the luminance response of $M$ cells were the basis of the apparent sparing of chromatic sensitivity (as described above), we would expect peak chromatic sensitivity to be found at higher temporal frequencies, as is characteristic of the luminance sensitivity of the P cell-deficient monkey (Merigan and Eskin, 1986). Instead, residual sensitivity to isoluminant stimuli was low pass in each monkey, suggesting detection by $P$ cells. We have observed sparing of small numbers of central $P$ cells in the lateral geniculate nucleus of some acrylamideexposed monkeys that we have studied morphologically. Such cells might provide the minimal residual chromatic sensitivity we have observed here.

\section{References}

Adams, A. J. (1982) Chromatic and luminosity processing in retinal disease. Am. J. Optom. Physiol. Optics 59: 954-960.

Bedford, R. E., and G. Wyszecki (1957) Axial chromatic aberration of the human eye. J. Opt. Soc. Am. 47: 564-565.

Bowmaker, J. K., H. J. A. Dartnall, J. N. Lythgoe, and J. D. Mollon (1978) The visual pigments of rods and cones in the rhesus monkey. J. Physiol. (Lond.) 274: 329-348.

Boynton, R. M., and N. Kambe (1986) Chromatic difference steps of moderate size measured along theoretically critical axes. Color Res. Appl. 5: 13-23.

Cavanagh, P. (1988) Interunit variability of equiluminance points does not mediate the contribution of color to motion. Invest. Ophthalmol. Vis. Sci. 29: 327.

Dartnall, H. J. A., J. K. Bowmaker, and J. D. Mollon (1983) Human visual pigments: Microspectrophotometric results from the eyes of seven persons. Proc. R. Soc. London [Biol.] 220: 115-130.

De Monasterio, F. M., and P. Gouras (1975) Functional properties of ganglion cells of the rhesus monkey retina. J. Physiol. (Lond.) 251: 167-195.

Derrington, A. M., and P. Lennie (1984) Spatial and temporal contrast sensitivities of neurons in lateral geniculate nucleus of macaque. $J$. Physiol. (Lond.) 357: 219-240.

Derrington, A. M., J. Krauskopf, and P. Lennie (1984) Chromatic mechanisms in lateral geniculate nucleus of macaque. J. Physiol. (Lond.) 357: 241-265.

DeValois, R. L., H. C. Morgan, M. C. Polson, W. R. Mead, and E. M. Hull (1974) Psychophysical studies of monkey vision, I. Macaque luminosity and color vision tests. Vision Res. 14: 53-68.

Eskin, T. A., and W. H. Merigan (1986) Selective acrylamide-induced degeneration of color opponent ganglion cells in macaques. Brain Res. 378: 379-384.

Gouras, P., and E. Zrenner (1979) Enhancement of luminance flicker by color-opponent mechanisms. Science 205: 587-589.

Hicks, T. P., B. B. Lee, and T. R. Vidyasager (1983) The responses of cells in the macaque lateral geniculate nucleus to sinusoidal gratings. J. Physiol. (Lond.) 337: 183-200.

Hurlbert, A. C., N. K. Logothetis, E. R. Charles, and P. H. Schiller (1987) The processing of color and luminance information in monkeys. Soc. Neurosci. Abstr. 13: 204.

Ingling, C. R., and E. Martinez-Uriegas (1983) The relationship between spectral sensitivity and spatial sensitivity for the primate $r-g$ X-channel. Vision Res. 23: 1495-1500.

Kaplan, E., and R. M. Shapley (1982) X and Y cells in the lateral geniculate nucleus of macaque monkeys. J. Physiol. (Lond.) 330:125143.

Kelly, D. H. (1979) Motion and vision. II. Stabilized spatiotemporal threshold surface. J. Opt. Soc. Am. 69: 1340-1349.

Kelly, D. H. (1983) Spatiotemporal variations of chromatic and achromatic contrast thresholds J. Opt. Soc. Am. 73: 742-750.

King-Smith, P. E., and D. Carden (1976) Luminance and opponentcolor contributions to visual detection and adaptation and to temporal and spatial integration. J. Opt. Soc. Am. 66: 709-717.

Koenderink, J. J., M. A. Bouman, A. E. Bueno de Mesquita, and S. Slappendel (1978) Perimetry of contrast detection thresholds of moving spatial sine wave patterns. J. Opl. Soc. Am. 68: 845-865.

Krauskopf, J., D. Williams, and D. W. Heeley (1982) Cardinal directions of color space. Vision Res. 22: 1123-1131.

Krauskopf, J., D. R. Williams, M. B. Mandler, and A. M. Brown (1986) Higher order color mechanisms. Vision Res. 26: 23-32.

Kruger, J. (1979) Responses to wavelength contrast in the afferent visual systems of the cat and the rhesus monkey. Vision Res. 19: 1351-1358.

Lee, B. B., P. R. Martin, and A. Valberg (1987) The physiological basis of heterochromatic flicker photometry. Invest. Ophthalmol. Vis. Sci. (Suppl.) 28: 240.

Lennie, P. (1980) Parallel pathways in the visual system. Vision Res. 20: 561-594.

Leventhal, A. G., R. W. Rodieck, and B. Dreher (1981) Retinal ganglion cell classes in the old world monkey: Morphology and central projections. Science 213: 1139-1142.

Livingston, M. S., and D. H. Hubel (1987) Psychophysical evidence for separate channels for the perception of form, color, movement, and depth. J. Neurosci. 7: 3416-3468.

MacLeod, D. I., and R. M. Boynton (1979) Chromaticity diagram showing cone excitation by stimuli of equal luminance. J. Opt. Soc. Am. 69: 1183-1186.

Merigan, W. H., and T. A. Eskin (1986) Spatio-temporal vision of macaques with severe loss of $\mathrm{Pb}$ retinal ganglion cells. Vision Res. 26: 1751-1761.

Mullen, K. T. (1985) The contrast sensitivity of human colour vision to red-green and blue-yellow chromatic gratings. J. Physiol. (Lond.) 359: $381-400$.

Nunn, B. J., J. L. Schnapf, and D. A. Baylor (1984) Spectral sensitivity of single cones in the retina of Macaca fascicularis. Nature 309:264266.

Perry, V. H., R. Oehler, and A. Cowey (1984) Retinal ganglion cells which project to the dorsal lateral geniculate nucleus in the macaque monkey. Neuroscience 12: 1101-1123.

Purpura, K., E. Kaplan, and R. M. Shapley (1988) Background light and the contrast gain of primate $\mathrm{P}$ and $\mathrm{M}$ retinal ganglion cells. Proc. Natl. Acad. Sci. USA 85: 4534-4537.

Rodieck, R. W., K. F. Binmoeller, and J. Dineen (1985) Parasol and midget ganglion cells of the human retina. J. Comp. Neurol. 233: 115-132.

Schiller, P. H., and C. L. Colby (1983) The responses of single cells 
in the lateral geniculate nucleus of the rhesus monkey to color and luminance contrast. Vision Res. 23: 1631-1641.

Schnapf, J. L., T. W. Kraft, and D. A. Baylor (1987) Spectral sensitivity of human cone photoreceptors. Nature 325: 439-441.

Shapley, R. M., and E. Kaplan (1986) What are the P and M cells of the monkey visual system sensitive to? Soc. Neurosci. Abstr. 12: 7.

Shapley, R., and V. H. Perry (1986) Cat and monkey retinal ganglion cells and their visual functional roles. Trends Neurosci. 9: 229-235.

Smith, V. C., and J. Pokorny (1975) Spectral sensitivity of the foveal cone photopigments between 400 and $500 \mathrm{~nm}$. Vision Res. 15: 161171.

Sperling, H. G., and R. S. Harwerth (1971) Red-green cone interactions in the increment-threshold spectral sensitivity of primates. Science 172: 180-184.

Stromeyer, C. F., G. R. Cole, and R. E. Kronauer (1987) Chromatic suppression of cone inputs to the luminance flicker mechanism. Vision Res. 27: 1113-1137.

Thibos, L. N., F. E. Cheney, and D. J. Walsh (1987) Retinal limits to the detection and resolution of gratings. J. Opt. Soc. Am. 4: 15241529.
Thornton, J., and E. N. Pugh (1983) Red/green color opponency at detection threshold. Science 219: 191-193.

Toolell, R. B. H., S. I. Hamilton, E. Switkes, and R. L. De Valois (1985) $2 \mathrm{DG}$ as a "functional HRP" in macaque striate cortex. Invest. Opthalmol. Vis. Sci. (Suppl.) 26: 9.

van der Horst, G., and M. A. Bouman (1969) Spatiotemporal chromaticity discrimination. J. Opt. Soc. Am. 59: 1482-1488.

Varner, D., D. Jameson, and L. M. Hurvich (1984) Temporal sensitivities related to color theory. J. Opt. Soc. Am. I: 474-481.

Virsu, V., B. B. Lee, and O. D. Creutzfeldt (1987) Mesopic spectral responses and the purkinje shift of macaque lateral geniculate nucleus cells. Vision Res. 27: 191-200.

Wiesel, T. N., and D. H. Hubel (1966) Spatial and chromatic interactions in the lateral geniculate body of the rhesus monkey. J. Neurophysiol. 29: 1115-1156.

Young, R. A. (1986) Principal-component analysis of macaque lateral geniculate nucleus chromatic data. J. Opt. Soc. Am. 3: 1735-1742. 